\title{
Is there any variability in the level of cortisol, corticosterone and cortisone of healthy volunteers versus women and men with elevated cholesterol?
}

\author{
Lucyna Konieczna', Aleksandra Puch-Walczak', \\ Tomasz Zdrojewski², Tomasz Bączek ${ }^{1}$ ()
}

${ }^{1}$ Department of Pharmaceutical Chemistry, Medical University of Gdańsk, Gdańsk, Poland

${ }^{2}$ Department of Prevention and Didactics, Medical University of Gdańsk, Gdańsk, Poland

\begin{abstract}
Background: Cardiovascular diseases with the accompanied elevated level of total cholesterol have been a major problem in society for the last several decades. They belong to the diseases of civilization which affect people at an increasingly young age. For this reason, our aim was to investigate whether the concentrations of selected steroids are related to elevated total cholesterol in people without diagnosed cardiovascular diseases. Material and methods: The study involved 71 plasma samples. 19 of them were obtained from women and men with elevated cholesterol levels, whereas 52 samples were from healthy volunteers (control group). Liquid chromatography coupled with mass spectrometry (LC-MS) validated method followed by solid-phase extraction procedure were applied to measure the plasma concentrations of the three endogenous glucocorticosteroids (cortisol, corticosterone and cortisone). Results: Statistically significant differences between the concentration of cortisol were noted among healthy women and women with elevated cholesterol. The measured concentrations of cortisol in healthy women and men are comparable, $111.19 \mathrm{ng} / \mathrm{mL}$ and $112.22 \mathrm{ng} / \mathrm{mL}$. respectively. However, the concentrations of cortisol in the elevated cholesterol group was significantly lower among women with elevated cholesterol than in healthy women $(74.13 \mathrm{ng} / \mathrm{mL}$ and $111.19 \mathrm{ng} / \mathrm{mL}$ respectively). The concentration of cortisol for men with elevated cholesterol was $38.60 \mathrm{ng} / \mathrm{mL}$. Hence, it is much higher than in women with elevated cholesterol and higher than in the case of healthy men. Distinctive changes can be observed also for corticosterone measured for both women and men. Conclusions: The observed differences on the level of steroids between healthy control group and patients with elevated cholesterol can be considered as worthy of further investigation from both biochemical as well as clinical points of view.
\end{abstract}

Keywords: Cardiovascular diseases · Elevated cholesterol · Steroids · Women and men

\section{Citation}

Is there any variability in the level of cortisol, corticosterone and cortisone of healthy volunteers versus women and men with elevated cholesterol? Eur J Transl Clin Med. 2021;4(2):68-74.

DOI: $10.31373 /$ ejtcm/122777 


\section{Introduction}

According to the data from World Health Organization, cardiovascular diseases are one of the most common causes of death worldwide and accounts for more than $50 \%$ of all deaths annually [1]. Biomarkers of cardiovascular disease play a vital role in accurate risk stratification. The biomarkers of cardiovascular disease include lipid panel [2], cardiac troponin [3], C-reactive protein [4], interleukin 6 [5], natriuretic peptides [6], homocysteine [7] or creatine kinase [8].

Steroid hormones are relatively easily accessible in biological materials and serve as a valuable source of information on patient's state of health and can also facilitate making the correct diagnosis. Of all steroid hormones, aldosterone has the greatest share in the pathogenesis of cardiovascular disease. Apart from its role in increasing in blood pressure (via increased potassium loss and the retention of sodium and water in the kidneys), its proinflammatory activity is also conducive to fibrosis of the heart muscle [9] Endogenous steroids were of interest in clinical and preclinical studies as biological indicators (biomarkers) of various diseases resulting from steroid disturbances e.g. bladder and renal cancers [10-11]. Data concerning hypothesis that hormone-related factors can be associated with stress (e.g. measuring urinary cortisol, cortisone and corticosterone in parachutists and depressed patients) were also documented as well as it was suggested that steroid hormones influence the growth of neuroendocrine tumors [12-13].

A number of analytical methods can be developed to determine endogenous steroid hormone in different biological fluids, including gas chromatography, liquid chromatography and capillary electrophoresis. Liquid chromatography considered as reversed phase liquid chromatography (RPLC) [14], especially in combination with mass spectrometry is commonly used for biomedical and pharmaceutical purposes. Attempts to find the alternatives are also considered, like the use of micellar liquid chromatography (MLC) [15]. However, liquid chromatography coupled with mass spectrometry (LC-MS) is yet considered to be the most effective method for biomedical goals with respect to steroid analysis due to its specificity and versatility [16-17].

The aim of the study was to investigate whether the concentrations of selected steroids (corticosterone, cortisol and cortisone) are related to elevated total cholesterol in people without diagnosed cardiovascular diseases.

\section{Material and methods}

\section{A Chemicals and reagents}

Standard substances (with high performance liquid chromatography purity) of cortisol, corticosterone and cortisone

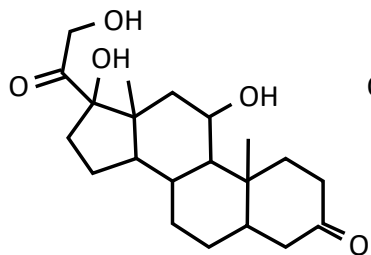

cortisol

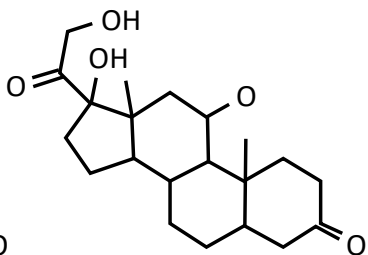

cortisone

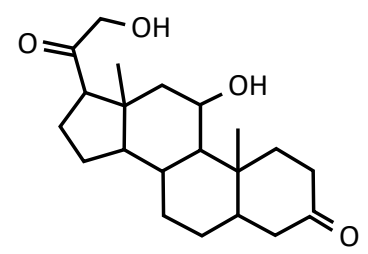

corticosterone

Figure 1. Chemical structures of three glucocorticosteroids considered in the study: cortisol, corticosterone and cortisone

(Figure 1) were obtained from Sigma (St. Louis, USA). Formic acid, methanol, acetonitrile and chloroform with HPLC purity were purchased from Sigma (St. Louis, USA). Ultrapure water was obtained from the Milli-Q purification system (Millipore, Bedford, USA).

Standard solutions of all analytical steroid standards: corticosterone, cortisol, cortisone were prepared in the following concentrations: $1 \mathrm{mg} / \mathrm{mL}, 10 \mathrm{\mu g} / \mathrm{mL}, 1 \mu \mathrm{g} / \mathrm{mL}$ and $100 \mathrm{ng} /$ $\mathrm{mL}$. Acetonitrile was used as a solvent to prepare $1 \mathrm{mg} / \mathrm{mL}$ reference solutions. The detection and quantification limits were determined based on a low concentration liquid chromatography coupled with mass spectrometry (LC-MS) analysis $(0.05-10 \mathrm{ng} / \mathrm{mL})$ of standard steroid hormone solutions. No interference between the steroids, the internal patterns and endogenous compounds in the matrix was demonstrated.

\section{LC-MS equipment}

A reversed phase liquid chromatography system (RPLC) from Agilent Technologies, Model 1260 Infinity (Agilent Technologies, Santa Clara, USA) was used, with the 1260 Bin Pump G1312B, 1260 Degasser G1322A, 1260 Autosampler G1329A, 1290 Thermostat G1330B, 1260 VWD G1314F, and a Poroshell 120 EC-C18 chromatography column (Agilent Technologies, St. Clara, USA) measuring $3.0 \times 100 \mathrm{~mm} ; 2.7 \mu \mathrm{m}$.

The assays were performed using combined techniques: a liquid chromatograph coupled with a mass spectrometer (Agilent Technologies, Santa Clara, USA), equipped with an electrospray ion source and a single quadrupole analyzer (Single Quadrupole 6120 LC-MS, G6120B). Chemstation Rev. B.04.02 SP1 software was used to collect and process the chromatographic data. (Agilent Technologies, Santa Clara, 
USA). The mobile phase consisted of $0.1 \%$ formic acid in Millipore grade water (eluent $A$ ) and $0.1 \%$ formic acid in LC-MS grade methanol (eluent $B$ ).

The analytical method was validated with respect to linearity, accuracy, precision and specificity. Based on the obtained results, the standard deviation and the limit of detection (LOD) and limit of quantitation (LOQ) values were calculated, which were respectively $0,06 \mathrm{ng} / \mathrm{mL}$ and $0,2 \mathrm{ng} /$ $\mathrm{mL}$. The analytical method used had a linear relationship between the amount of analyte present in the sample and the area of the resulting chromatographic peak.

\section{Solid-phase extraction equipment}

Plasma samples were prepared based on solid-phase extraction method. For solid-phase extraction we used Supelco Discovery DSC-18, $500 \mathrm{mg} 6 \mathrm{ml}$ standard polypropylene (PP) - tubes (Sigma, St. Louis, USA), Supelco Supel - Select HLB, $500 \mathrm{mg} 6 \mathrm{ml}$ standard PP - tubes (Sigma, St. Louis, USA), LiChrolut RP-18, $500 \mathrm{mg} 6 \mathrm{ml}$ standard PP - tubes (Merck, Darmstadt, Germany) and Sep-Pak C-18, $500 \mathrm{mg} 6 \mathrm{ml}$ standard PP - tubes (Waters, Milford, USA), along with the Vacuum Extraction Kit - VacElut SPS 24 Manifold (Agilent Technologies, Santa Clara, USA). The Vacuum Concentrator was from CentriVap Aqueous System (Labconco, Kansas City, USA). The corresponding optimization of sample preparation involved the choice of the appropriate extraction sorbent.

In the case of the Supelco Supel - Select HLB, LiChrolut RP-18 and Sep-Pak C-18, the preliminary analysis of certified blank plasma samples indicated that the matrix was not cleaned sufficiently well. Additionally, the analysis of plasma sample spiked with known concentration of analytes confirmed that their measured concentration levels were lower using mentioned the above columns in comparison to the Supelco Discovery DSC-18. Hence, the latter choice of the extraction sorbent was Supelco Discovery DSC-18 due to higher back-concentration achieved and closer to the real spiked one.

\section{Sample preparation}

The plasma samples were centrifuged $(10,000 \mathrm{rpm}, 7 \mathrm{~min})$. Then, $250 \mu \mathrm{L}$ of each sample was put into the described rotor tube. Next, $1 \mu \mathrm{g} / \mathrm{mL}$ of betamethasone standard solution was added as internal standards. The tubes were mixed on a Vortex laboratory shaker (IKA Werke GmbH \& Co.KG, Staufen, Germany) for 30 seconds, then each of them was measured with $3 \mathrm{~mL}$ of deionized water and remixed on the Vortex shaker (30 s). The tubes were transferred to a shaker (amplitude $300,10 \mathrm{~min})$. At the end of shaking the tubes were centrifuged (10,000 rpm, $7 \mathrm{~min})$.

Supelco Discovery DSC-18 columns were used for the extraction of plasma samples, which were activated with $2 \times 2$ $\mathrm{mL}$ methanol and $2 \times 2 \mathrm{~mL}$ deionized water, not allowing the bed to dry. Then the plasma specimens were prepared on the columns. The samples were purified with $2 \times 2 \mathrm{~mL}$ deionized water. In the next stage, the bed was dried ( $15 \mathrm{~min})$. After this time, the analytes were eluted from the bed using $2 \times 1 \mathrm{~mL}$ of methanol. The contents of the eluate tubes were then evaporated to dryness in a vacuum concentrator at $50^{\circ} \mathrm{C}$.

The dry evaporation residue was dissolved in $100 \mu \mathrm{L}$ of $80 \%$ methanol and mixed on a Vortex laboratory shaker (30 s), then transferred to Eppendorf tubes and centrifuged $(10,000 \mathrm{rpm}, 7 \mathrm{~min})$. The contents of the tubes were then placed in the inserts and analyzed by LC-MS.

\section{Study population and sample collection}

71 plasma samples were collected, including 19 from women and men with elevated cholesterol (total cholesterol levels more than 180 milligrams per deciliter, identified on the basis of the provided biochemical parameters within the diagnostic analysis) and 52 from healthy volunteers. Women and men with elevated cholesterol were not yet diagnosed with any cardiovascular diseases (e.g. ischemic heart disease, coronary artery disease, myocardial infarction, hypertension, atrial fibrillation). All participants were diagnosed at the Department of Hypertension and Diabetology of the Medical University of Gdańsk.

All statistical analyses were conducted using STATISTICA 10.0 software (TIBCO Software Inc, Palo Alto, USA). The hormone levels were log-transformed prior to statistical analyses. Using log-transformation we obtained normal distribution of individual concentration data. The statistical significance of intergroup differences was verified with the parametric tests with $p<0.05$. The Student's t-test for independent samples was used as the inference tests, according to assumptions of normal distribution - checked with Shapiro-Wilk test and Kolmogorov-Smirnov test. Homoscedasticity (homogeneity of variance) was checked with Levene's test and Brown-Forsythe test. If the assumption of homogeneity of variance was not fulfilled, Welch's t-test (unequal variances t-test) was applied. If the assumption of normal distribution was not fulfilled, Mann-Whitney U test was applied.

The samples were prepared to determine the calibration curves, which in turn allowed for the calculation of mean concentrations of individual steroid hormones and standard deviations by the least squares method.

\section{Results}

The obtained results expressed as mean concentrations of individual glucocorticosteroids measured in $\mathrm{ng} / \mathrm{mL}$ are collected in Table 1. As it can be seen, The mean concentration of cortisol in healthy women was $111.19 \mathrm{ng} / \mathrm{mL}$ and it was highly similar to the mean concentration of that glucocorticosteroid measured in men $(112.22 \mathrm{ng} / \mathrm{mL})$. However, a different trend can be observed for the concentrations of cortisol in the elevated cholesterol group: the mean concentration 
Table 1. Collected data for three tested glucocorticosteroids in healthy volunteers and patients with elevated cholesterol

\begin{tabular}{|c|c|c|c|c|}
\hline \multicolumn{2}{|c|}{ Women } & \multicolumn{2}{c|}{ Men } \\
\hline Glucocorticosteroid & $\begin{array}{c}\text { Healthy volunteers } \\
(\mathrm{N}=28)\end{array}$ & $\begin{array}{c}\text { Elevated cholesterol } \\
(\mathrm{N}=9)\end{array}$ & $\begin{array}{c}\text { Healthy volunteers } \\
(\mathrm{N}=23)\end{array}$ & $\begin{array}{c}\text { Elevated cholesterol } \\
(\mathrm{N}=10)\end{array}$ \\
\hline Cortisol $[\mathrm{ng} / \mathrm{m}]$ & $\begin{array}{c}\text { Mean }=111.19 \\
\mathrm{SD}=57.42\end{array}$ & $\begin{array}{c}\text { Mean }=74.13 \\
\mathrm{SD}=42.95\end{array}$ & $\begin{array}{c}\text { Mean }=112.22 \\
\mathrm{SD}=47.75\end{array}$ & $\begin{array}{c}\text { Mean }=138.60 \\
\mathrm{SD}=106.26\end{array}$ \\
\hline Corticosterone $[\mathrm{ng} / \mathrm{mL}]$ & $\begin{array}{c}\text { Mean }=6.50 \\
\mathrm{SD}=5.07\end{array}$ & $\begin{array}{c}\text { Mean }=4.48 \\
\mathrm{SD}=3.48\end{array}$ & $\begin{array}{c}\text { Mean }=13.30 \\
\mathrm{SD}=32.52\end{array}$ & $\begin{array}{c}\text { Mean }=6.72 \\
\mathrm{SD}=8.42\end{array}$ \\
\hline Cortisone $[\mathrm{ng} / \mathrm{mL}]$ & $\begin{array}{c}\text { Mean }=21.2905 \\
\mathrm{SD}=9.1669\end{array}$ & $\begin{array}{c}\text { Mean }=22.3572 \\
\mathrm{SD}=13.1252\end{array}$ & $\begin{array}{c}\text { Mean }=21.4927 \\
\mathrm{SD}=9.9549\end{array}$ & $\begin{array}{c}\text { Mean }=23.1119 \\
\mathrm{SD}=13.5998\end{array}$ \\
\hline
\end{tabular}

of cortisol was much lower among women with elevated cholesterol than in healthy women $(74.13 \mathrm{ng} / \mathrm{mL}$ and 111.19 $\mathrm{ng} / \mathrm{mL}$ respectively). On the contrary, for men with elevated cholesterol the concentration of cortisol was $38.60 \mathrm{ng} / \mathrm{mL}$. Hence, it was much higher than in women with elevated cholesterol and higher than in the case of healthy men.

Considering corticosterone, generally lower mean concentrations of that glucocorticosteroid were noted in comparison to the mean concentrations of cortisol (Table 1). The mean concentration of corticosterone assessed in healthy women was $6.50 \mathrm{ng} / \mathrm{mL}$ and was higher than the mean concentration of that hormone measured in women with elevated cholesterol $(4.48 \mathrm{ng} / \mathrm{mL})$. Similar trend was observed for the group of men. Here also the mean concentration of corticosterone was higher in healthy volunteers in comparison to men with elevated cholesterol $(13.30 \mathrm{ng} / \mathrm{mL}$ vs. $6.72 \mathrm{ng} / \mathrm{mL})$. It is noteworthy that this difference the concentrations of corticosterone was greater between the studied groups of men than groups of women.

The most stable concentration results were obtained for cortisone (Table 1). In all four tested groups of participants, the mean concentrations of cortisone were in the range of $21.29-23.11 \mathrm{ng} / \mathrm{mL}$. Specifically, for healthy women the mean concentration of cortisone was $21.29 \mathrm{ng} / \mathrm{mL}$, and for women with elevated cholesterol was $22.35 \mathrm{ng} / \mathrm{mL}$. Hence, only slightly higher mean concentration of cortisone was found for women with elevated cholesterol. Similar situation was noted among men: the mean concentration of cortisone was $21.49 \mathrm{ng} / \mathrm{mL}$ for healthy men and $23.11 \mathrm{ng} / \mathrm{mL}$ in men with elevated cholesterol. Once again, as in the case of women, only a slightly higher mean concentration of cortisone was found in men with elevated cholesterol.
The most distinctive differences were noted in cortisol level for tested groups of women. A statistically significant decrease in the concentration of cortisol in women with elevated cholesterol in contrary to healthy women was noted ( $p<0.03$; Student's t-test). It is not a very strong significance, as confirmed additionally by a box plot (see Figure 2 ). Nevertheless, it is a trend indicating a potential influence of variable cortisol concentration in both studied groups. Although the mean concentration of cortisol evaluated in men with elevated cholesterol is much higher in comparison to the concentration of cortisol in women with elevated cholesterol, there were no statistically significant differences noted between the healthy men and men with elevated cholesterol ( $p<0.96$; Welch's t-test).

No statistically significant differences in corticosterone concentrations were found in the two groups of interest. Hence, no statistically significant differences were noted between healthy volunteers and women and men with elevated cholesterol in the case of women $(p<0.26$; Student's t-test). Although the absolute difference between mean concentrations of corticosterone measured for men is almost twice higher for the group of healthy volunteers in comparison to women and men with elevated cholesterol, again no statistically significant differences are found $(p<$ 0.91; Mann-Whitney U test).

Finally, the results for cortisone are similar for all tested groups, as confirmed via statistical analysis. No statistically significant differences for the mean concentrations of cortisone can be observed between healthy volunteers and women and men with elevated cholesterol in the case of women $(p<0.92$; Student's t-test). Also, no statistically significant 
differences for the mean levels of cortisone were found analyzing healthy volunteers and women and men with elevated cholesterol in the case of men ( $p<0.96$ Student's t-test).

\section{Discussion}

In our study, we demonstrated that cortisol level is higher in healthy female volunteers than in those with elevated cholesterol. There were no other significant differences in cortisol levels between men. Corticosterone and cortisone level was similar in any studied subgroup.

Cortisol, an essential glucocorticoid, is regulated by two izoenzymes that affect its metabolism. However, individual daily changes of cortisol level could alter diagnostic studies, including our findings [18]. It has been demonstrated that hair or plasma cortisol level correlates with stress, obesity, depression, cardiac diseases, stroke and diabetes [19-20]. Owing to the importance of glucocorticosteroids on human health, we showed that the elevated cholesterol level correlates with decreased cortisol level in women. The current dogma is that when cortisol is released, it elevates the cholesterol level. The described physiological reaction to stress has short duration, although long-term effects such as diseases are well-known consequences. On the cellular level, only a few studies directly explain the possible connection between cholesterolsynthesis, release and its influence on cortisol [21]. Oxysterol-related-binding-protein, a lipid binding protein, was found to influence both cholesterol homeostasis and cortisol synthesis [21]. Interestingly, this protein contributed to the reduction of cellular level of oxysterols and binds 11-deoxycholesterol. In another study, ATR-101 in adrenocortical cells was investigated to control of cholesterol level [22]. Based on our results, we assume that plasma cortisol level is subject to daily changes. Furthermore, a significantly lowered cortisol level in females while the cholesterol was elevated, although an interesting finding, could be in fact accidental. the adrenal cortex prevents accumulation of toxic level of cholesterol and is therefore unique in its multifunctional role. To date, this relation remains poorly investigated.

On the other hand, we demonstrated that cholesterol level is not altered by corticosterone and cortisone levels. Our findings conflict with studies on the cellular level using laboratory animals. Corticosterone administration for two weeks dysregulated cholesterol levels in chickens, in whom cholesterol was accumulated in muscle cells [23]. The administration of cortisone influenced total cholesterol level in rabbits [24]. More studies on humans are yet to be published. One study clearly demonstrated that cortisone-to-cortisol ratio in females did not correlate with type 2 diabetes mellitus [26]. On the contrary, in our study corticosterone level was reduced in both men and women.

On a population level, hypercholesterolemia remains a clinical challenge. According to large cohort observational studies, an increased cholesterol level ( $\geq 190 \mathrm{mg} / \mathrm{dl}$ ) was diagnosed in one-half of the screened population [25]. It seems that public awareness campaigns and further research developing better cholesterol control and finding its relations with glucocorticosteoids are needed.

\section{Conclusions}

We noted statistically significant differences in the case of tested levels of cortisol between healthy women volun-

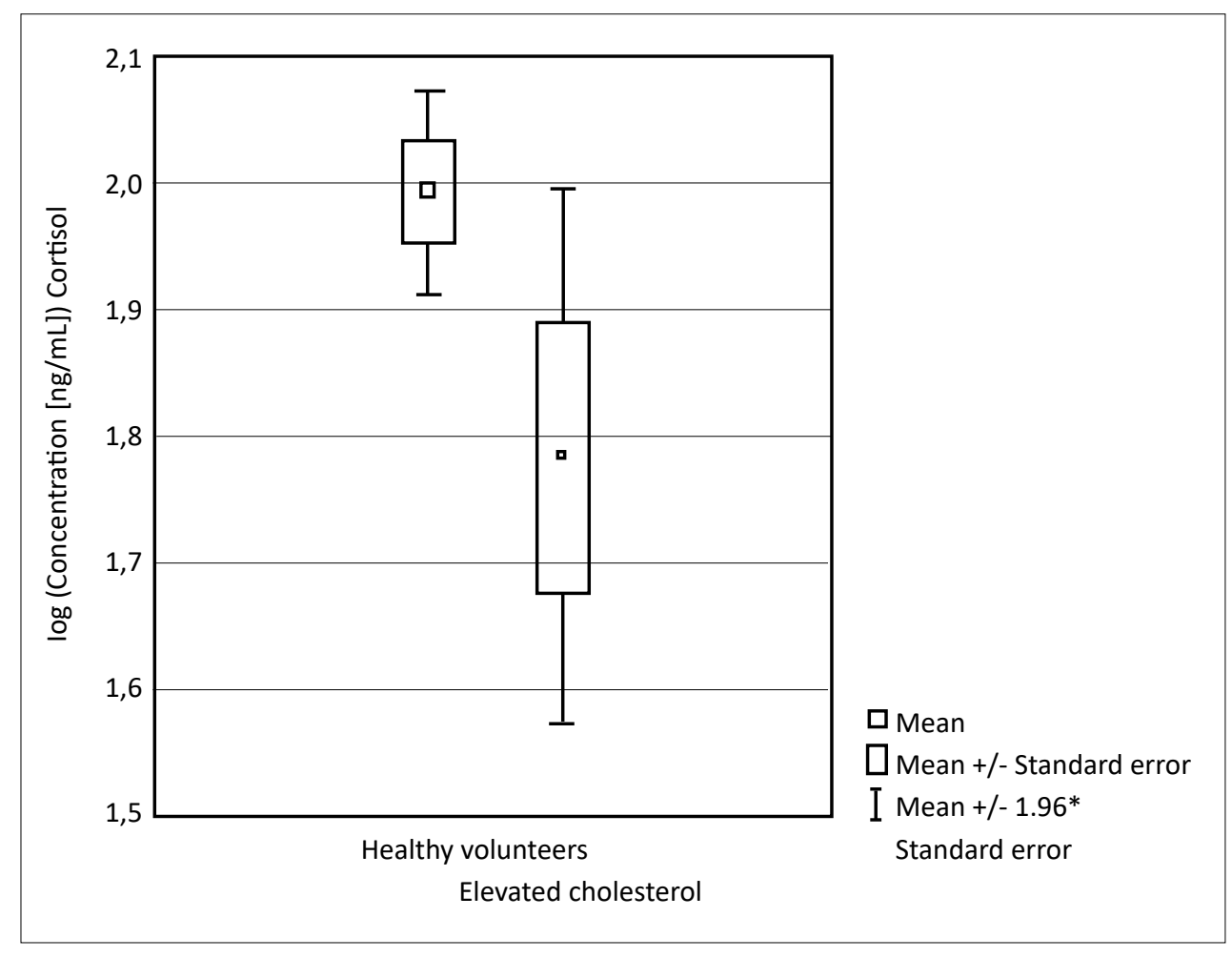

Figure 2. Box plot showing the statistical significance of the cortisol levels in healthy women vs. women with elevated cholesterol 
teers and women with elevated cholesterol. In other groups evaluated within one gender (women or men), no statistically significant differences were found. The found differences in the level of steroids between healthy volunteers and people with elevated cholesterol can be considered worthy of further investigation from both biochemical as well as clinical points of view.

\section{Conflicts of interest}

Conflict of interest: none declared.

The authors declare that the study complies with the Declaration of Helsinki. A locally-appointed ethics committee approved the research protocol and informed consent was obtained from the subjects.

\section{References}

1. Vittos O, Toana B, Vittos A, Moldoveanu E. Lipoprotein-associated phospholipase A2 (LP-PLA2): a review of its role and significance as a cardiovascular biomarker. Biomarkers. 2012;17:289-302. Available from: https://www.tandfonline.com/ doi/full/10.3109/1354750X.2012.664170

2. National Cholesterol Education Program, Third report of the National Cholesterol Education Program (NCEP), Expert panel on detection, evaluation and treatment of high blood cholesterol in adults (ATP III). Circulation. 2002;17:3143-3421. Available from: https://www.ncbi.nlm.nih.gov/pubmed/12485966

3. Thygesen K, Mair J, Katus H, Plebani M, Venge P, Collinson P, Lindahl B, Giannitsis E, Hasin Y, Galvani M, Tubaro M, Alpers SJ, Biasucci ML, Koenig W, Mueller Ch, Huber K, Hamm Ch, Jaffe SA. Recommendations for the use of cardiac troponin measurement in acute cardiac care. Eur Heart J. 2010;31:2197-2206. Available from: https://www.ncbi.nlm.nih.gov/ pubmed/20685679

4. Myers LG, Rifai N, Tracy PR, Roberts LW, Alexander WR, Biasucci ML, Cartavas DJ, Cole GT, Cooper RG, Khan VB, Kimberly MM, Stein AE, Taubert AK, Warnick RG, Waymack PP. CDC/AHA Workshop on markers of inflammation and cardiovascular disease: application to clinical and public health practice: report from the Laboratory Science Discussion Group. Circulation. 2004;110:545-549. Available from: https://www.ncbi.nlm.nih.gov/pubmed/15611379

5. Ridker MP, Rifai N, Stampfer JM, Hennekens HCh. Plasma concentration of interleukin-6 and the risk of future myocardial infarction among apparently healthy men. Circulation. 2000;101:1767-1772. Available from: https://www.ahajournals. org/doi/full/10.1161/01.cir.101.15.1767

6. Thygesen K, Mair J, Katus H, Plebani M, Venge P, Collinson P, Lindahl B, Giannitsis E, Hasin Y, Galvani M, Tubaro M, Alpers SJ, Biasucci ML, Koenig W, Mueller Ch, Huber K, Hamm Ch, Jaffe SA. Recommendations for the use of natriuretic peptides in acute cardiac care. Eur Heart J. 2012;33:2001-2006. Available from: https://www.ncbi.nlm.nih.gov/pubmed/21292681

7. Antoniades Ch, Antonopoulos SA, Tousoulis D, Marinou K, Stefanadis Ch. Homocysteine and coronary atherosclerosis: from folate fortification to the recent clinical trials. Eur Heart J. 2009;30:6-15. Available from: https://www.meta.org/ papers/homocysteine-and-coronary-atherosclerosis-from/19029125

8. Saenger KA. A tale of two biomarkers: the use of troponin and CK-MB in contemporary practice. Clin Lab Sci. 2010;23:134140. Available from: https://www.ncbi.nlm.nih.gov/pubmed/20734885

9. Gaddam KK, Pimenta E, Husain S, Calhoun AD. Aldosterone and cardiovascular disease. Curr Probl Cardiol. 2009;34:5184. Available from: https://www.ncbi.nlm.nih.gov/pubmed/19135616

10. Nozaki O. Steroid analysis for medical diagnosis. J Chromatogr A 2001;935:267-278. Available from: https://www.ncbi. nlm.nih.gov/pubmed/11762779

11. Konieczna L, Bączek T, Belka M, Fel A, Markuszewski M, Struck W, Markuszewski M, Kaliszan R. Steroid profiles' as potential biomarkers in patients with urogenital tract cancer for diagnostic investigations analyzed by liquid chromatography coupled to mass spectrometry. J Pharm Biomed Anal 2013;73:108-115. Available from: https://www.ncbi.nlm.nih.gov/ pubmed/22475516

12. Plenis A, Konieczna L, Olędzka I, Kowalski P, Bączek T. Simultaneous determination of urinary cortisol, cortisone and corticosterone in parachutists, depressed patients and healthy controls in view of biomedical and pharmacokinetic studies. Mol BioSyst 2011;7:1487-1500. Available from: https://www.ncbi.nlm.nih.gov/pubmed/21336389

13. Plenis A, Miękus N, Olędzka I, Bączek T, Lewczuk A, Woźniak Z, Koszałka P, Seroczyńska B, Skokowski J. Chemometric evaluation of urinary steroid hormone levels as potential biomarkers of neuroendocrine tumors. Molecules 2013;18:1285712876. Available from: https://www.ncbi.nIm.nih.gov/pmc/articles/PMC6269673/ 
14. Plenis A, Konieczna L, Miękus N, Bączek T. Development of the HPLC method for simultaneous determination of lidocaine hydrochloride and tribenoside along with their impurities supported by the QSRR approach chromatographia. Chromatographia 2013;76:255-265. Available from: https://www.ncbi.nlm.nih.gov/pubmed/23482886

15. Kawczak P, Bączek T. Recent theoretical and practical applications of micellar liquid chromatography (MLC) in pharmaceutical and biomedical analysis. Cent Eur J Chem 2012;10:570-584. Available from: https://link.springer.com/article/10.2478/s11532-012-0004-7

16. Shackleton C. Clinical steroid mass spectrometry: a 45 -year history culminating in HPLC-MS/MS becoming an essential tool for patient diagnosis. J Steroid Biochem Mol Biol 2010;121:481-490. Available from: https://europepmc.org/article/ med/20188832

17. Antignac JP, Brosseaud A, Gaudin-Hirret I, André F, Le Bizec B. Analytical strategies for the direct mass spectrometric analysis of steroid and corticosteroid phase II metabolites. Steroids 2005;70:205-216. Available from: https://www.ncbi. nlm.nih.gov/pubmed/15763600

18. Gastpar H. [Physiological significance and pharmacological action of heparin]. Thromb Diath Haemorrh Suppl [Internet]. 1965;16:1-130. Available from: http://www.ncbi.nlm.nih.gov/pubmed/5334212

19. van der Valk ES, van der Voorn B, Iyer AM, Mohseni M, Leenen PJM, Dik WA, et al. Hair cortisol, obesity and the immune system: Results from a 3 year longitudinal study. Psychoneuroendocrinology [Internet]. 2021 Dec;134:105422. Available from: https://www.sciencedirect.com/science/article/pii/S0306453021002961

20. Sepp N, Zelger B, Schuler G, Romani N, Fritsch P. Sneddon's Syndrome - An Inflammatory Disorder of Small Arteries Followed by Smooth Muscle Proliferation. Am J Surg Pathol [Internet]. 1995 Apr;19(4):448-53. Available from: http:// www.ncbi.nlm.nih.gov/pubmed/7694946

21. Teale JD, Forman EJ, King LJ, Marks V. Production of antibodies to tetrahydrocannabinol as the basis for its radioimmunoassay. Nature [Internet]. 1974 May 10;249(5453):154-5. Available from: http://www.ncbi.nlm.nih.gov/pu$\underline{\mathrm{bmed} / 4833515}$

22. Desai HG, Anklesaria ED. Ophthalmological aspects of tuberculous meningitis. J Indian Med Assoc [Internet]. 1967 Nov 1;49(9):429-32. Available from: http://www.ncbi.nlm.nih.gov/pubmed/5595769

23. Duan Y, Fu W, Wang S, Ni Y, Zhao R. Cholesterol deregulation induced by chronic corticosterone (CORT) stress in pectoralis major of broiler chickens. Comp Biochem Physiol Part A Mol Integr Physiol [Internet]. 2014 Oct;176:59-64. Available from: https://linkinghub.elsevier.com/retrieve/pii/S1095643314001354

24. Parrish KM, Higuchi S, Stinson FS, Dufour MC, Towle LH, Harford TC. Genetic or cultural determinants of drinking: A study of embarrassment at facial flushing among Japanese and Japanese-Americans. J Subst Abuse [Internet]. 1990 Jan;2(4):439-47. Available from: http://www.ncbi.nlm.nih.gov/pubmed/2136126

25. Rutkowski M, Wierucki $Ł$, Wojciechowska A, Zdrojewski T. The effectiveness of screening for major cardiovascular risk factors in the population of small towns in Poland. Eur J Transl Clin Med [Internet]. 2021;4(1):57-64. Available from: http://dx.doi.org/10.31373/ejtcm/133107

26. Eames WB. The amalgam vs. composite controversy. J Colo Dent Assoc [Internet]. 62(6):4-5. Available from: http://www. ncbi.nlm.nih.gov/pubmed/6589245 